\title{
$\mathrm{RCP} 8.5$ 시나리오를 이용하여 온량지수에 따른 천안시 적응 가능한 식물종 연구*
}

\author{
공석준 · 신진호 · 양금철 \\ 공주대학교 건설환경공학부
}

\section{The Study of Adaptable Plant Species according to Warmth Index using RCP 8.5 Scenarios in Cheonan-Si*}

\author{
Kong, Seok Jun · Shin, Jin Ho and Yang, Keum Chul \\ Dept. of Civil \& Environmental Eng. Kongju National University.
}

\begin{abstract}
This study was proposed to adaptable species according to climate change using warmth index(WI) in Cheonan-Si. RCP 8.5 was used to estimate change of warmth index(WI) depending on climate change in Cheonan-Si. Climatic change of Cheonan-Si was estimated to change from cool temperate forest central zone to warm temperate forest zone.

The following plant species will survive within WI change of Cheonan-Si from 2010 to $2050: 18$ species in the tree layer including Quercus serrata, Q. variabilis, Pinus densiflora, Q. acutissima etc.; 28 species in the shrub layer including Rhus trichocarpa, Lindera obtusiloba, Zanthoxylum schinifolium etc.; 24 species in the herb layer including Oplismenus undulatifolius, Carex lanceolata, etc.; 12 species in the vine plants including Smilax china, Cocculus trilobus, etc.
\end{abstract}

Key Words : Cool temperate forest central zone, Warm temperate forest zone.

*본 연구는 환경부 2012 차세대에코이노베이션기술 개발사업의 지원으로 수행되었음.

First author : Kong, Seok Jun, Dept. of Civil \& Environmental Eng. Kongju National University, Tel : +82-41-521-9311, E-mail : chaos008@kongju.ac.kr

Corresponding author : Yang, Keum Chul, Dept. of Civil \& Environmental Eng. Kongju National University, Tel : +82-41-521-9311, E-mail : yangkc@ kongju.ac.kr

Received : 7 February, 2013. Revised : 1 April, 2013. Accepted : 10 May, 2013. 


\section{I. 서 론}

산업혁명 이후 화석연료 사용이 급격하게 늘 어남에 따라 대기 중 온실가스의 농도가 증가하 였으며, 현재 이산화탄소의 농도는 $400 \mathrm{ppm}$ 까지 올라갔다. 기후변화는 열파, 가뭄, 홍수 등 극한 기상현상을 일으키며, 해수면 상승 등 지구생태 계 전반에 걸쳐 광범위한 영향을 끼치고 있다 (이현우, 2010).

지난 100여 년(1912 2008년)간 한반도의 평 균 기온 상승률은 $1.7^{\circ} \mathrm{C}$ 로 전 지구 평균기온 상승 률 $0.741 \pm 0.003^{\circ} \mathrm{C}$ 에 비해 높게 나타났다(국립기 상연구소, 2009). 또한 IPCC(Intergovernmental Panel on Climate Change) 4 차 평가 보고서의 기온 전망에 따르면 향후 100 년간 지구의 기온은 1.8 $4.0^{\circ} \mathrm{C}$ 가 상승할 것으로 전망하였다. 이러한 지구 평균기온의 상승은 생태계의 구조와 기능, 종, 생 태계 상호 작용, 종의 지리적 분포에 부정적인 영 향을 미치며, 동 - 식물 종의 약 20 30\%가 멸종 위기에 처한다고 전망했다(IPCC, 2007). 식생 발 달에 관련하여 영향을 미치는 주요한 환경인자로 는 기후, 토양, 지형 등의 무기적 환경조건과 생물 간 경쟁 등의 규제 조건이 각각의 생물에 작용하 여 생육지를 제한하기 때문에 종류에 따라 생육장 소가 각각 정해져 있다. 일반적으로 중위도 이상 에서 식생 성장에 가장 중요한 기후요소는 기온과 강수량으로 알려져 있으며, 한반도와 같이 강수량 이 충분한 곳에서는 기온이 주요 인자가 된다(Suh et al., 2005).

도시 녹지는 인간의 교란에 따른 파편화, 고립 화 등으로 서식지로서의 가치보다는 개발의 논 리가 앞서서 훼손되거나 소멸된 곳들이 많으며 (김귀곤 등, 2000), 조경위주의 도시녹지공간 조 성으로 인하여 자연생태와 이질적인 형태를 보 이고 있다(정흥락 등, 2007). 이러한 도시 산림생 태계내 자생식물군집의 파괴로 인하여 생물종다 양성이 낮아지고, 식생구조의 불균형을 초래하 였으며 단일수종에 의하여 우점하는 현상이 나
타나고 있다(Hough, 1983). 이러한 현상은 산림 생태계내 목본식물 및 민감성이 높은 초본식물 이 환경오염에 의한 쇠퇴징후의 심각성이 표면 화되면서 자연성 회복을 위한 복원모델의 제시 가 요구되고 있다(강현경 - 방광자, 2001).

이경재 등 $(1995 ; 1996)$ 은 서울을 중심으로 한 훼손된 생태계의 식생복원에 대한 연구를 통해 도시지역의 녹지복원용 수종선발, 녹지내 식생 의 생태적 층위구조를 고려한 식생도입방안 및 녹지조성방안을 제시하였다. 오구균(1986)은 기 후에 맞는 수종선정 및 상호작용과 생태적 지위 를 고려한 식재설계 방향을 제시하였고, 심우경 (1988)은 조경배식 설계에 관한 연구에서 식물 종선정 시 적지적수의 중요성을 강조하여 식물 소재의 향토성과 환경내성, 관리성 등의 객관적, 합리적, 과학적 근거를 지닌 적수평가표를 통한 계량적 평가지표를 제안하였다. 박종철 등(2010) 은 기후변화에 따른 난온대 상록활엽수림대의 이동에 관한 연구를 통해 지구온난화에 따른 난 온대 상록활엽수림대의 이동을 분석하였으며, 윤종학 등(2011)은 기후변화에 따른 한반도 난 온대 상록활엽수의 잠재 생육지 변화 예측에 관 한 연구에서 CT-model을 이용하여 현재기후 (1961 1990)와 3종류의 미래기후(2081 2100) 시 나리오(CCCMA-A2, CSIRO-A2, HADCM3-A2)를 이용하여 잠재 생육지를 예측하였다. 이러한 연 구들은 도시생태계의 복원을 위한 연구이거나, 기후변화에 따른 한반도의 난온대 상록활엽수종 또는 상록활엽수림의 생육지 변화에 대한 연구 이다. 반면 변정연 등(2012)은 시공간 정보를 기 반으로 산림생태계의 기후변화 취약성에 대한 평가연구를 하였으나 이는 기후변화에 따른 생 산성을 중심으로 연구한 결과로 기후변화에 따 른 구체적인 적응 수종에 대한 연구는 미흡한 실 정이다.

따라서 본 연구에서는 IPCC 4차보고서에서 제공하는 기후변화 시나리오 중 RCP 8.5 를 이용 하여 지역(천안시)에 적응 가능한 식물종을 제시 
하고자 한다. 이러한 연구는 향후 기후변화에 따 른 각 지역에 적합한 식재수종 혹은 복원종의 정 보를 제공하는 자료로 활용 가능할 것이다.

\section{II. 재료 및 방법}

\section{1. 연구대상지}

천안시는 충청남도의 동북부에 위치하고 (Figure 1) 있으며, 총 인구는 595,756명이며, 행 정구역은 4 개읍, 8 개면, 행정동 16 개동으로 전 체 면적은 $636.07 \mathrm{~km}^{2}$ 이다(천안통계연보). 중앙 에 남북을 가로 지르는 차령산맥의 줄기인 태조 산(424m)을 중심으로 동 - 서측으로 지역이 분 리되어 있고, 북측지역은 평택평야까지 탁 트인 얕은 구릉성 평지로 이루어져 있다. 식물구계지 리학상 한반도 중부아구(Lee and Yim, 1978)에 속하며, 식생의 군계수준에서 냉온대 중부(Yim and Kira, 1975)에 해당한다. 천안시의 기후는 대체로 온난하나 기온의 교차가 비교적 큰 대륙 성 기후를 나타내며, 1 월 평균기온은 $-2.9^{\circ} \mathrm{C}, 8$ 월 평균기온은 $25.1^{\circ} \mathrm{C}$, 연평균기온은 $11.8^{\circ} \mathrm{C}$ 이 었으며, 연강수량은 $1,226.5 \mathrm{~mm}$ 으로 나타났다 (천안기상대, 1980 2010년 평균).

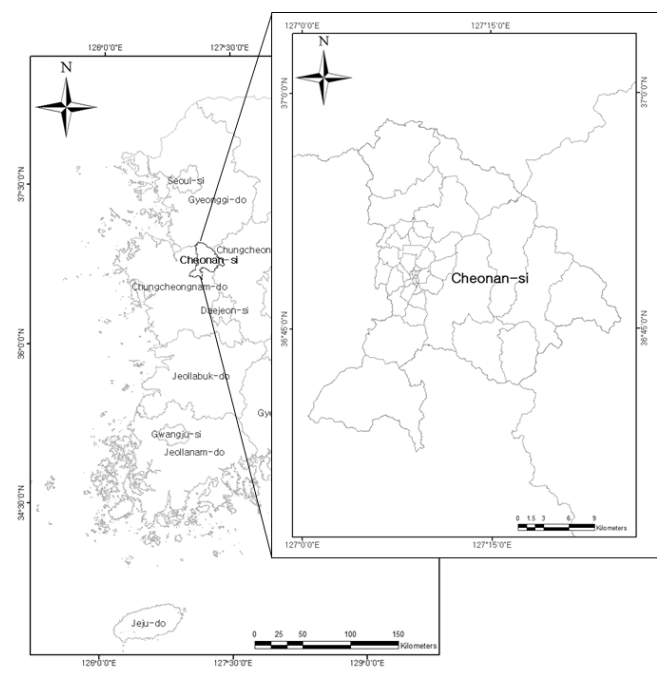

Figure 1. Map of study sites.

\section{2. 기후자료}

\section{1 현재기후구축}

현재의 기후자료는 기상청에서 제공하고 있 는 67개 관측소(Figure 2) 최근 30년(1981 2010년)간의 평균기온을 이용하였으며, 이를 이 용하여 남한의 온량지수(WI : Warmth Index)분 포를 구하였다. 온량지수란 식물이 잘 성장하기 위해서는 기준온도 이상의 온도가 일정기간 이 상 유지되어야 한다는 개념으로 Kira (1945)가 제안한 기후를 표시하는 지수 중 하나이다. 국 내에서 Yim (1977)이 우리나라의 식생분포를 설명하기 위해 사용하였으며, 식물생장의 유효 열량(Effective heat for plant)과 관계가 있다. 온 량지수는 $5^{\circ} \mathrm{C}$ 보다 높은 월평균 기온의 합으로 계산할 수 있다.

$$
W I=\sum_{1}^{n}(t-5), t>5^{\circ} \mathrm{C} \quad t: \text { 월평균기온 }
$$

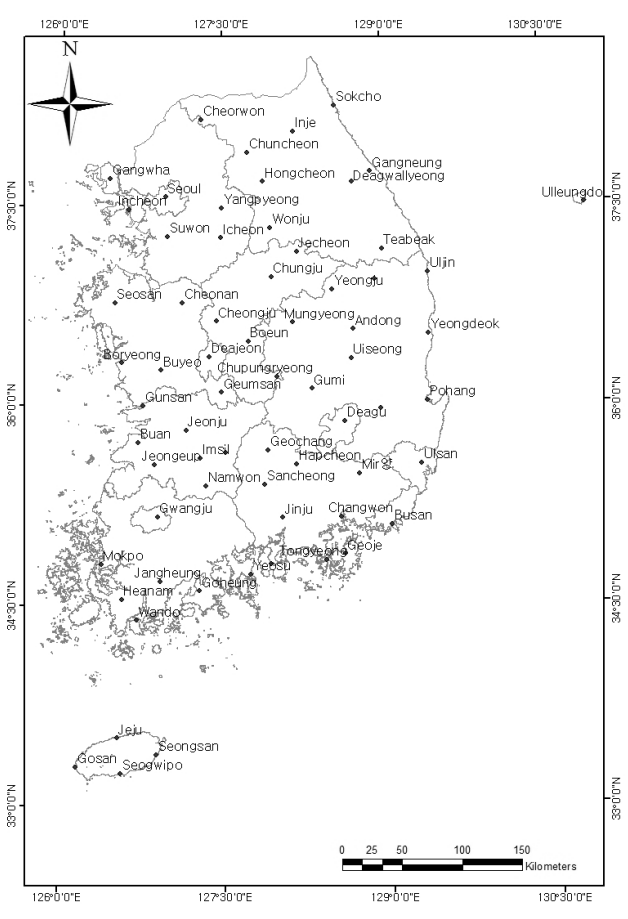

Figure 2. Location of meteorological observation station in South Korea. 

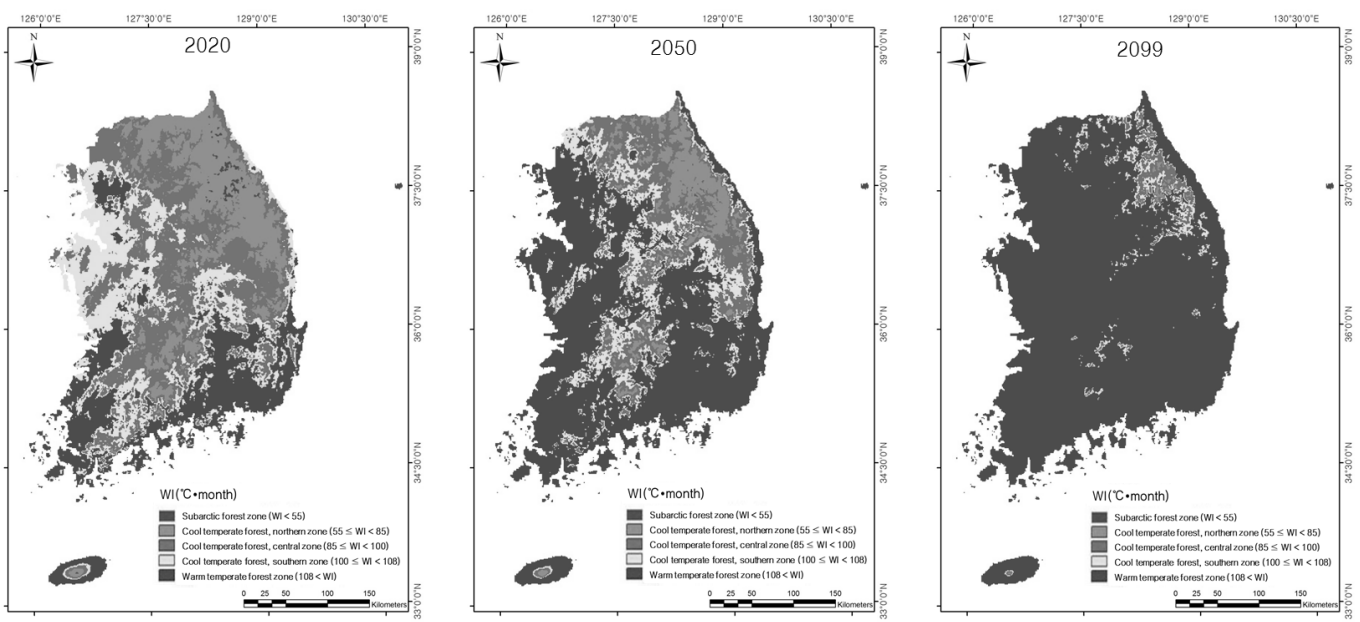

Figure 3. Change in Forest zone of S. Korea according to RCP 8.5 Scenarios.

온량지수에 의한 산림기후대의 구분은 난온 대림은 $\mathrm{WI} \geq 108^{\circ} \mathrm{C} \cdot \mathrm{month}$, 냉온대 남부림은 $108>\mathrm{WI} \geq 100^{\circ} \mathrm{C} \cdot$ month, 냉온대 중부림은 $100^{\circ} \mathrm{C} \cdot$ month $>$ WI $\geq 85^{\circ} \mathrm{C} \cdot$ month, 냉온대 북부림은 $85^{\circ} \mathrm{C} \cdot$ month $>\mathrm{WI} \geq 55^{\circ} \mathrm{C} \cdot$ month, 아한대림은 $\mathrm{WI}<55^{\circ} \mathrm{C} \cdot \operatorname{month}$ 로 구분된다 (Yim \& Kira, 1975; 양금철, 2001).

\section{2 미래기후구축}

미래 기후자료는 기상청의 기후변화정보센터 (http://www.climate.go.kr)에서 제공하고 있는 RCP 8.5 를 이용한 결과를 ESRI ASCII GRID 형태의 파일을 사용하였다. 남한의 상세자료의 격자 크기는 $1 \mathrm{~km} \times 1 \mathrm{~km}$ 이었으며, 월평균기온 을 이용하여 2020년, 2050년, 2099년에 대한 온 량지수를 산정하였다(Figure 3).

\section{3. 온량지수 변화에 따른 식물종의 분포분석}

우리나라의 자생 식물종은 205과 1,162속 4,961 종(Nature 국가생물종 지식정보시스템, http:// www.nature.go.kr)이 분포하고 있는 것으로 알려 졌다. 그 중 식물종의 분포는 Arc GIS 프로그램 을 이용하여 국립환경과학원의 전국자연환경조 사 통해 조사된 식물종과 생물자원관의 표본 식
물종의 위치정보를 가지고 있는 1,522 종에 대하 여 분포도를 작성하였다(Figure 4). 작성한 식물 종의 분포와 현재 온량지수 분포를 중첩해 1,522 종에 대한 온도에 따른 분포특성을 분석하였다.

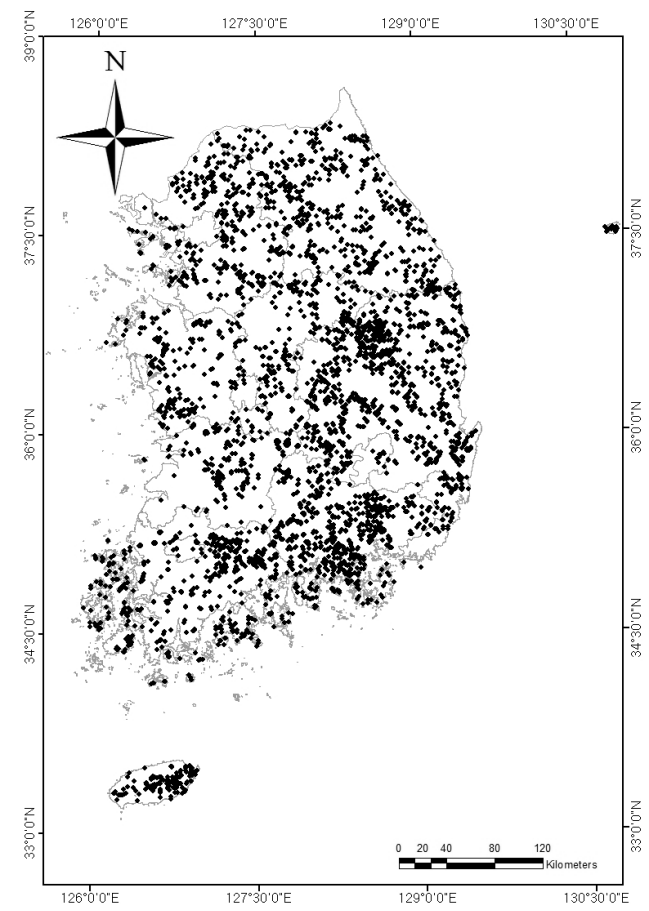

Figure 4. Distribution of 1,522 major plant species. 


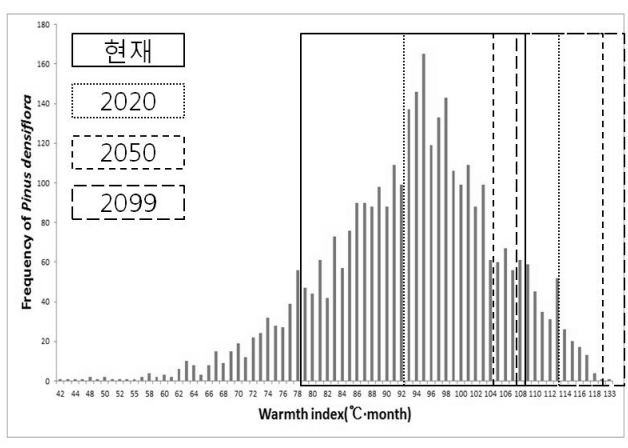

Figure 5. Selection of adaptable plant species according to RCP 8.5 scenarios in Cheonan-Si

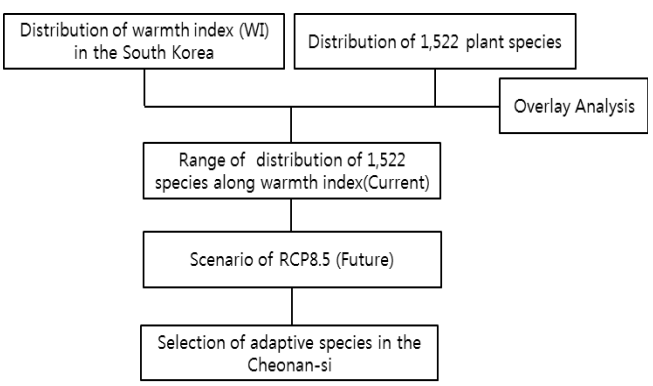

Figure 6. Flow chart of the study.

분석된 1,522 종의 온량지수 분포특성에 대하 여 천안시의 현재 온량지수 및 기후변화에 따른 2020년, 2050년, 2099년의 온량지수 변화를 중 첩하여 천안시에 적응 가능한 식물종을 선정하 였다(Figure 5).
앞서 구한 미래기후의 온량지수분포와 식물 종별 온량지수분포범위를 비교하여 미래기후에 적절한 식물종에 대해 선정하였다. 연구의 흐름 은 Figure 6과 같다.

\section{III. 결과 및 고찰}

\section{1. 온량지수에 따른 식물종의 분포특성}

최근 30 년간의 평균기온으로 산출한 남한의 온량지수 분포는 $25 \sim 143^{\circ} \mathrm{C} \cdot \operatorname{month}$ 의 범위를 가졌으며, 아한대림, 냉온대 북부·중부·남부 림, 난온대림의 5 개의 산림기후대를 가지는 것 으로 나타났다. 남한의 평균 온량지수는 $94.2^{\circ} \mathrm{C}$. month로 산정되었으며, 평균 온량지수에 의한 산림기후대는 냉온대 중부림에 해당하였다. 우 리나라에 분포하고 있는 식물종 중 위치정보를 가진 1,522 종 중 100 회 이상의 출현빈도를 가지 는 식물종은 308종으로 나타났다. 온량지수 분 포범위가 넓은 교목성 식물 7종을 살펴보면 Table 1과 같다.

졸참나무의 온량지수의 분포역은 $35 \sim 134^{\circ} \mathrm{C}$. month로 나타났으며, 평균 온량지수는 $95.9^{\circ} \mathrm{C} \cdot$ month로 산정되었고, 냉온대 중부림에서 $48 \%$ 로 가장 많이 분포하는 것으로 나타났다. 이러한 결 과는 남한에서의 졸참나무 우점림의 온량지수 분포역 $53 \sim 117^{\circ} \mathrm{C} \cdot$ month, 최적범위 WI 90

Table 1. Range of distribution of 7 species along Warmth Index (WI).

\begin{tabular}{|c|c|c|c|c|c|c|c|c|c|}
\hline \multirow[b]{2}{*}{ Species } & \multirow[b]{2}{*}{ Frequency } & \multicolumn{3}{|c|}{$\mathrm{WI}\left({ }^{\circ} \mathrm{C} \cdot \mathrm{month}\right)$} & \multirow{2}{*}{$\begin{array}{c}\text { Subarctic } \\
\text { forest zone } \\
\mathrm{WI}<55 \\
(\%)\end{array}$} & \multicolumn{3}{|c|}{ Cool temperate forest } & \multirow{2}{*}{$\begin{array}{c}\text { Warm temperate } \\
\text { forest zone } \\
108 \leq \mathrm{WI} \\
(\%)\end{array}$} \\
\hline & & Min & $\operatorname{Max}$ & Mean & & $\begin{array}{c}\text { northern zone } \\
55 \leq \mathrm{WI}<85 \\
(\%)\end{array}$ & $\begin{array}{c}\text { central zone } \\
85 \leq \mathrm{WI}<100 \\
(\%)\end{array}$ & $\begin{array}{c}\text { southern zone } \\
100 \leq \mathrm{WI}<108 \\
(\%)\end{array}$ & \\
\hline Quercus serrata & 4,283 & 35 & 134 & 95.9 & 0.3 & 13.8 & 48 & 22.7 & 15.2 \\
\hline Quercus mongolica & 4,215 & 35 & 118 & 84.8 & 2.9 & 41.7 & 44.9 & 8.5 & 2 \\
\hline Quercus variabilis & 3,866 & 50 & 118 & 93.3 & 0.1 & 20 & 52.4 & 17.1 & 10.4 \\
\hline Pinus densiflora & 3,374 & 42 & 133 & 93.4 & 0.4 & 19.9 & 50 & 18.9 & 10.8 \\
\hline Quercus acutissima & 1,723 & 55 & 128 & 98.6 & 0 & 5.7 & 49.7 & 29.8 & 14.8 \\
\hline Quercus aliena & 1,638 & 41 & 118 & 96.4 & 0.2 & 8.9 & 53.2 & 25.5 & 12.2 \\
\hline Quercus dentata & 1,240 & 36 & 120 & 91.5 & 0.2 & 24.7 & 51.2 & 18.1 & 5.7 \\
\hline
\end{tabular}


Table 2. Change in warmth index of Cheonan-Si according to climate change.

\begin{tabular}{ccccc}
\hline & 2010 & \multicolumn{3}{c}{ RCP 8.5 scenarios } \\
\cline { 3 - 5 } & $77 \sim 103$ & $84 \sim 109$ & 2050 & 2099 \\
\hline $\begin{array}{c}\text { WI range } \\
\left({ }^{\circ} \mathrm{C} \cdot \text { month }\right)\end{array}$ & $96.1 \pm 4.8$ & $100.6 \pm 5.3$ & $95 \sim 122$ & $122 \sim 151$ \\
\hline $\begin{array}{c}\text { WI average } \\
\left({ }^{\circ} \mathrm{C} \cdot \text { month }\right)\end{array}$ & $\begin{array}{c}\text { Cool temperate forest, } \\
\text { Central zone }\end{array}$ & $\begin{array}{c}\text { Cool temperate forest, } \\
\text { Southern zone }\end{array}$ & $\begin{array}{c}\text { Warm temperate } \\
\text { forest zone }\end{array}$ & $\begin{array}{c}\text { Warm temperate } \\
\text { forest zone }\end{array}$ \\
\hline Forest zone
\end{tabular}
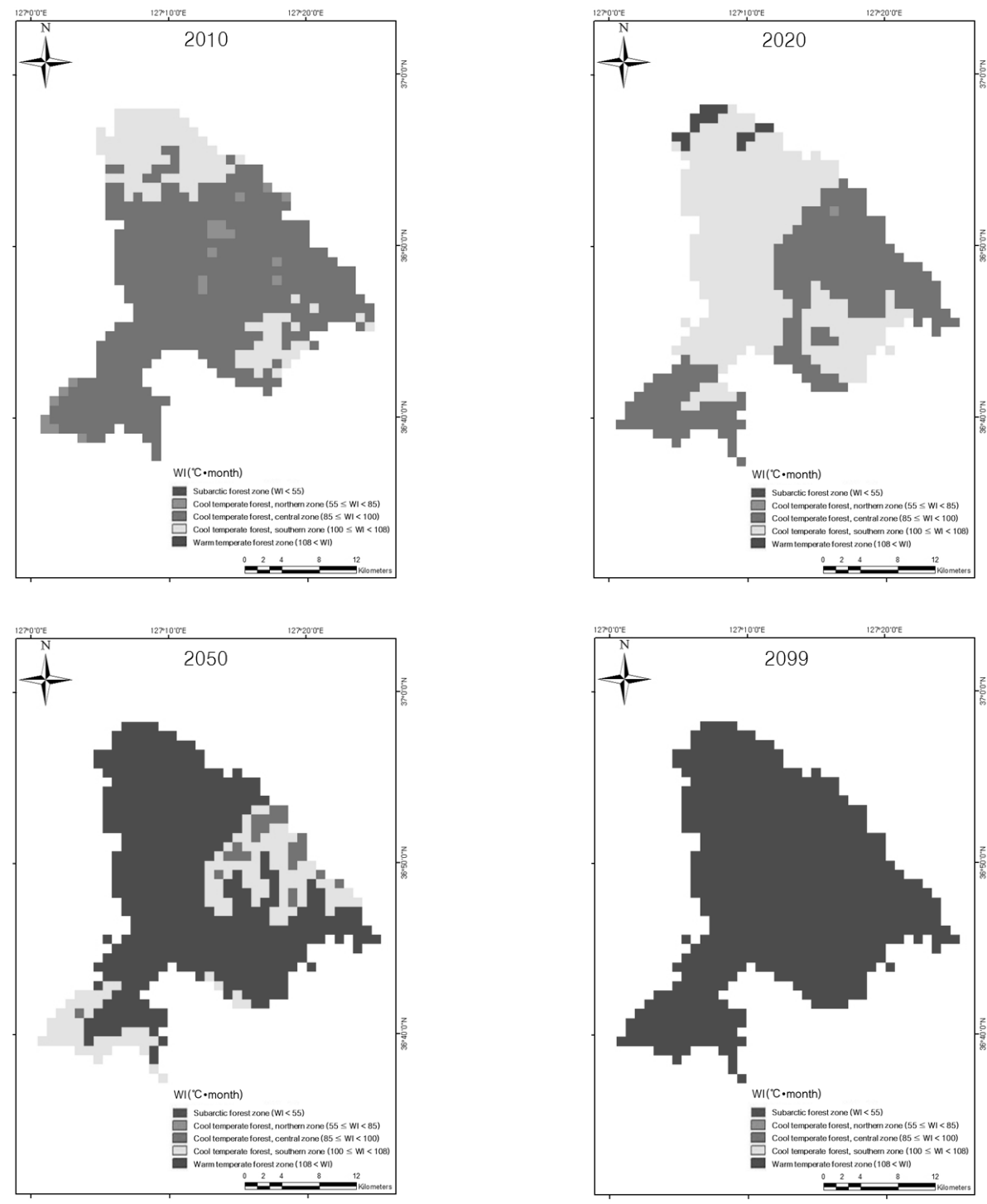

Figure 7. Change in forest zone of Cheonan-Si according to climate change. 
$105^{\circ} \mathrm{C} \cdot \mathrm{month}$ 에서 $62.8 \%$ 로 가장 많이 분포하 며, 평균 WI $92^{\circ} \mathrm{C} \cdot \mathrm{month}$ 라고 한 양금철(2001) 의 연구결과와 유사한 것으로 나타났다.

굴참나무의 온량지수 분포역은 $50 \sim 118^{\circ} \mathrm{C}$ · month의 범위를 가졌으며, 온량지수 $85 \sim 100^{\circ} \mathrm{C}$. month에 해당하는 냉온대 중부림에서 $52.4 \%$ 로 가장 많이 나타났고, 평균 $\mathrm{WI}$ 는 $93.3^{\circ} \mathrm{C} \cdot \mathrm{month}$ 로 산정되었다. 양금철(2001)은 굴참나무 우점 림의 온량지수 분포역 $56 \sim 115^{\circ} \mathrm{C} \cdot$ month 범위 를 가지며, 최적범위 $90 \sim 100^{\circ} \mathrm{C} \cdot \mathrm{month}$ 에서 $58.3 \%$ 로 나타났고, 평균 $\mathrm{WI} 93^{\circ} \mathrm{C} \cdot \operatorname{month}$ 라 하 였는데 본 연구결과 역시 그 범위에 포함되는 것으로 나타났다.

소나무의 온량지수 분포는 $42 \sim 133^{\circ} \mathrm{C} \cdot$ month 의 범위에서 나타났으며, 평균 온량지수는 $93.4^{\circ} \mathrm{C} \cdot \mathrm{month}$ 로 산정되었고, 산림기후대 중 냉온대 중부림에 해당하는 범위 $85 \sim 100^{\circ} \mathrm{C}$ month에서 $50 \%$ 로 가장 많이 분포하는 것으로 나타났다. 양금철(2001)은 소나무 우점림의 온 량지수 분포역이 $47 \sim 120^{\circ} \mathrm{C} \cdot \mathrm{month}$ 의 범위를 가지며, 최적범위는 $\quad 90 \sim 100^{\circ} \mathrm{C} \cdot \mathrm{month}$ 에서 $58.3 \%$ 로 나타났고, 평균 $\mathrm{WI} 93^{\circ} \mathrm{C} \cdot \mathrm{month}$ 라 하 였는데 본 연구결과와 유사하게 나타났다.

상수리나무의 온량지수 분포범위는 $55 \sim 128^{\circ} \mathrm{C}$ · month에서 나타났으며, 산림기후대 중 냉온대 중부림에서 $49.7 \%$ 로 가장 많이 분포하였으며, 평균 온량지수는 $98.6^{\circ} \mathrm{C} \cdot \mathrm{month}$ 로 산정되었다. 이는 양금철(2001)의 상수리나무 우점림의 온 량지수 분포역 $56 \sim 119^{\circ} \mathrm{C} \cdot \mathrm{month}$, 최적범위 90 $\sim 105^{\circ} \mathrm{C} \cdot \mathrm{month}$, 평균 $\mathrm{WI} 95^{\circ} \mathrm{C} \cdot \mathrm{month}$ 의 결 과와 유사하였다.

갈참나무의 경우 온량지수 분포역은 41 $118^{\circ} \mathrm{C} \cdot \operatorname{month}$ 로 나타났으며, 평균 온량지수는 $96.4^{\circ} \mathrm{C} \cdot \operatorname{month}$ 로 산정되었고, 냉온대 중부림에 서 $53.2 \%$ 로 가장 많이 분포하는 것으로 나타났 다. 이러한 결과는 남한에서 갈참나무 우점림의 온량지수 분포역 $60 \sim 111^{\circ} \mathrm{C} \cdot \mathrm{month}$ 범위를 가 졌고, 최적범위 $\mathrm{WI} \quad 90 \sim 100^{\circ} \mathrm{C} \cdot \mathrm{month}$ 에서
$56.4 \%$ 로 가장 많이 분포하며, 평균 $\mathrm{WI} 92^{\circ} \mathrm{C}$. month라고 한 양금철(2001)의 연구 결과와 유 사한 것으로 나타났다.

떡갈나무의 온량지수 분포역은 $36 \sim 120^{\circ} \mathrm{C}$. month로 나타났으며, 평균 온량지수는 $91.5^{\circ}$ $\mathrm{C} \cdot \mathrm{month}$ 로 산정되었고, 산림기후대 중 냉온대 중부림에서 $51.2 \%$ 로 가장 많이 분포하는 것으 로 나타났다. 이러한 결과는 남한에서 떡갈나무 우점림의 온량지수 분포역 $58 \sim 107^{\circ} \mathrm{C} \cdot \mathrm{month}$, 최적범위 WI $95 \sim 100^{\circ} \mathrm{C} \cdot \mathrm{month}$ 에서 $21.5 \%$ 로 가장 많이 분포하며, 평균 $\mathrm{WI} 88^{\circ} \mathrm{C} \cdot \operatorname{month}$ 라 고 한 양금철(2001)의 연구 결과와 유사하게 나 타났다.

\section{2. 천안시 기후변화}

천안시의 온량지수 평균에 따른 산림기후대 를 살펴보면 2010년(현재)은 냉온대 중부림에 해당하는 것으로 나타났으며, 온실가스 저감노 력 없이 지금과 같은 경제성장을 하였을 때의 시나리오인 RCP 8.5 를 이용하여 기후변화에 따 른 산림기후대의 변화를 살펴보면 2020년에 냉 온대 남부림 2050년과 2099년에는 난온대림에 해당하는 것으로 나타났다(Table 2).

또한 2010년 천안시 지역에 넓은 면적에서 나타나던 냉온대 중부림이 시간이 지남에 따라 점차 감소하고 2099년에는 난온대림으로 변화 하는 것으로 예상된다(Figure 7).

\section{3. 기후변화에 따른 천안시 적응 가능한 식물종 선정}

현재 식물종의 온량지수 분포와 기후변화에 따른 천안시 온량지수의 변화를 중첩하여 천안 시 적응 가능한 식물종을 선정하였다(Table 3). 2010년 현재 천안시 지역 온량지수 분포에 따 른 천안시에 적용하여 식재할 수 있는 식물종에 는 교목층에 졸참나무, 신갈나무, 굴참나무, 소 나무, 상수리나무 등이 나타났으며, 관목층에 생강나무, 개옻나무, 산초나무, 진달래, 싸리 등 
Table 3. Adaptable species according to climate change in Cheonan-Si.

\begin{tabular}{|c|c|c|c|c|}
\hline & 2010 & 2020 & 2050 & 2099 \\
\hline $\begin{array}{l}\text { Tree } \\
\text { layer }\end{array}$ & $\begin{array}{l}\text { Quercus serrata, Quercus } \\
\text { mongolica, Quercus } \\
\text { variabilis, Pinus densiflora, } \\
\text { Quercus acutissima, Prunus } \\
\text { sargentii, Quercus aliena, } \\
\text { Styrax japonica, Quercus } \\
\text { dentata, Lindera } \\
\text { erythrocarpa, Styrax obassia, } \\
\text { Fraxinus rhynchophylla, } \\
\text { Fraxinus sieboldiana, Sorbus } \\
\text { alnifolia, Platycarya } \\
\text { strobilacea, Morus bombycis, } \\
\text { Diospyros lotus, Potentilla } \\
\text { freyniana, Albizzia julibrissin, } \\
\text { Carpinus laxiflora, Prunus } \\
\text { leveilleana, Alnus hirsuta, } \\
\text { Acer mono, Trachelospermum } \\
\text { asiaticum var. intermedium, } \\
\text { Cornus kousa }\end{array}$ & $\begin{array}{l}\text { Quercus serrata, Quercus } \\
\text { variabilis, Pinus densiflora, } \\
\text { Quercus mongolica, Quercus } \\
\text { acutissima, Quercus aliena, } \\
\text { Styrax japonica, Prunus } \\
\text { sargentii, Quercus dentata, } \\
\text { Lindera erythrocarpa, Styrax } \\
\text { obassia, Fraxinus } \\
\text { rhynchophylla, Fraxinus } \\
\text { sieboldiana, Platycarya } \\
\text { strobilacea, Sorbus alnifolia, } \\
\text { Diospyros lotus, Albizzia } \\
\text { julibrissin, Morus bombycis, } \\
\text { Prunus leveilleana, Carpinus } \\
\text { laxiflora, Alnus hirsuta, } \\
\text { Trachelospermum asiaticum } \\
\text { var. intermedium, Potentilla } \\
\text { freyniana, Cornus kousa, } \\
\text { Celtis sinensis }\end{array}$ & $\begin{array}{l}\text { Quercus serrata, Quercus } \\
\text { variabilis, Pinus densiflora, } \\
\text { Quercus acutissima, Styrax } \\
\text { japonica, Quercus mongolica, } \\
\text { Quercus aliena, Prunus } \\
\text { sargentii, Lindera } \\
\text { erythrocarpa, Quercus } \\
\text { dentata, Platycarya } \\
\text { strobilacea, Fraxinus } \\
\text { sieboldiana, Sorbus alnifolia, } \\
\text { Albizzia julibrissin, Diospyros } \\
\text { lotus, Fraxinus } \\
\text { rhynchophylla, Celtis } \\
\text { sinensis, Styrax obassia, } \\
\text { Prunus leveilleana }\end{array}$ & $\begin{array}{l}\text { Neolitsea sericea, Machilus } \\
\text { thunbergii, Quercus glauca, } \\
\text { Celtis sinensis, Camellia } \\
\text { japonica, Castanopsis } \\
\text { cuspidata var. sieboldii, } \\
\text { Distylium racemosum, Tilia } \\
\text { miqueliana, Quercus acuta, } \\
\text { Idesia polycarpa, Lozoste } \\
\text { lancifolia }\end{array}$ \\
\hline $\begin{array}{l}\text { Shrub } \\
\text { layer }\end{array}$ & $\begin{array}{l}\text { Lindera obtusiloba, Rhus } \\
\text { trichocarpa, Zanthoxylum } \\
\text { schinifolium, Rhododendron } \\
\text { mucronulatum, Lespedeza } \\
\text { bicolor, Juniperus rigida, } \\
\text { Stephanandra incisa, } \\
\text { Ligustrum obtusifolium, } \\
\text { Atractylodes japonica, } \\
\text { Lespedeza maximowiczii, } \\
\text { Callicarpa japonica, Rubus } \\
\text { crataegifolius, Rhododendron } \\
\text { schlippenbachii, Corylus } \\
\text { heterophylla var. thunbergii, } \\
\text { Acer pseudo-Sieboldianum, } \\
\text { Rhus chinensis, Lindera } \\
\text { glauca, Rosa multiflora, } \\
\text { Indigofera kirilowii, Weigela } \\
\text { subsessilis, Rhododendron } \\
\text { yedoense var. poukhanense, } \\
\text { Securinega suffruticosa, } \\
\text { Viburnum erosum, Euonymus } \\
\text { alatus for. ciliato-dentatus, } \\
\text { Acer ginnala, Potentilla } \\
\text { fragarioides var. major, } \\
\text { Lespedeza cyrtobotrya, } \\
\text { Clerodendron trichotomum, } \\
\text { Rhododendron } \\
\text { mucronulatum var. ciliatum, } \\
\text { Rubus oldhamii, Rubus } \\
\text { parvifolius, Viburnum } \\
\text { dilatatum, Boehmeria spicata, } \\
\text { Corylus heterophylla, } \\
\text { Zanthoxylum piperitum, } \\
\text { Spiraea prunifolia for. } \\
\text { simpliciflora, Euonymus } \\
\text { alatus, Sapium japonicum, } \\
\text { Lespedeza x tomentella }\end{array}$ & $\begin{array}{l}\text { Lindera obtusiloba, Rhus } \\
\text { trichocarpa, Zanthoxylum } \\
\text { schinifolium, Rhododendron } \\
\text { mucronulatum, Juniperus } \\
\text { rigida, Lespedeza bicolor, } \\
\text { Ligustrum obtusifolium, } \\
\text { Stephanandra incisa, } \\
\text { Callicarpa japonica, } \\
\text { Atractylodes japonica, } \\
\text { Lespedeza maximowiczii, } \\
\text { Lindera glauca, Rubus } \\
\text { crataegifolius, Rosa } \\
\text { multiflora, Corylus } \\
\text { heterophylla var. thunbergii, } \\
\text { Indigofera kirilowii, Rhus } \\
\text { chinensis, Rhododendron } \\
\text { schlippenbachii, Acer } \\
\text { pseudo-Sieboldianum, } \\
\text { Rhododendron yedoense var. } \\
\text { poukhanense, Viburnum } \\
\text { erosum, Weigela subsessilis, } \\
\text { Euonymus alatus for. } \\
\text { ciliato-dentatus, Securinega } \\
\text { suffruticosa, Clerodendron } \\
\text { trichotomum, Viburnum } \\
\text { dilatatum, Lespedeza } \\
\text { cyrtobotrya, Rubus } \\
\text { parvifolius, Acer ginnala, } \\
\text { Rhododendron } \\
\text { mucronulatum var. ciliatum, } \\
\text { Rubus oldhamii, Zanthoxylum } \\
\text { piperitum, Potentilla } \\
\text { fragarioides var. major, } \\
\text { Boehmeria spicata, Corylus } \\
\text { heterophylla, Sapium } \\
\text { japonicum, Euonymus alatus, } \\
\text { Spiraea prunifolia for. } \\
\text { simpliciflora }\end{array}$ & $\begin{array}{l}\text { Rhus trichocarpa, Lindera } \\
\text { obtusiloba, Zanthoxylum } \\
\text { schinifolium, Rhododendron } \\
\text { mucronulatum, Juniperus } \\
\text { rigida, Ligustrum } \\
\text { obtusifolium, Lespedeza } \\
\text { bicolor, Lindera glauca, Rosa } \\
\text { multiflora, Stephanandra } \\
\text { incisa, Indigofera kirilowii, } \\
\text { Platycarya strobilacea, } \\
\text { Lespedeza maximowiczii, } \\
\text { Callicarpa japonica, } \\
\text { Atractylodes japonica, Rubus } \\
\text { crataegifolius, Rhus } \\
\text { chinensis, Corylus } \\
\text { heterophylla var. thunbergii, } \\
\text { Eurya japonica, Viburnum } \\
\text { erosum, Rhododendron } \\
\text { yedoense var. poukhanense, } \\
\text { Rhododendron } \\
\text { schlippenbachii, Rubus } \\
\text { parvifolius, Rhododendron } \\
\text { mucronulatum var. ciliatum, } \\
\text { Viburnum dilatatum, Celtis } \\
\text { sinensis, Zanthoxylum } \\
\text { piperitum, Weigela } \\
\text { subsessilis, Clerodendron } \\
\text { trichotomum, Acer } \\
\text { pseudo-Sieboldianum }\end{array}$ & $\begin{array}{l}\text { Litsea japonica, Mallotus } \\
\text { japonicus, Ficus erecta, } \\
\text { Eurya japonica, Ardisia } \\
\text { japonica, Ligustrum } \\
\text { obtusifolium, Lindera } \\
\text { obtusiloba, Ligustrum } \\
\text { japonicum, Ardisia crenata, } \\
\text { Euonymus japonica, Kadsura } \\
\text { japonica, Zanthoxylum } \\
\text { piperitum, Eurya japonica } \\
\text { var. aurescens, Rosa } \\
\text { multiflora, Cudrania } \\
\text { tricuspidata }\end{array}$ \\
\hline
\end{tabular}


Table 3. Continued.

\begin{tabular}{|c|c|c|c|c|}
\hline & 2010 & 2020 & 2050 & 2099 \\
\hline $\begin{array}{l}\text { Herb } \\
\text { layer }\end{array}$ & $\begin{array}{l}\text { Carex lanceolata, Spodiopogon } \\
\text { sibiricus, Aster scaber, Artemisia } \\
\text { keiskeana, Oplismenus } \\
\text { undulatifolius, Symplocos } \\
\text { chinensis for. pilosa, Pyrola } \\
\text { japonica, Disporum smilacinum, } \\
\text { Pteridium aquilinum var. } \\
\text { latiusculum, Polygonatum } \\
\text { odoratum var. pluriflorum, } \\
\text { Carex humilis, Arundinella } \\
\text { hirta, Smilax nipponica, Isodon } \\
\text { inflexus, Miscanthus sinensis } \\
\text { var. purpurascens, Carex } \\
\text { siderosticta, Calamagrostis } \\
\text { arundinacea, Chrysanthemum } \\
\text { zawadskii var. latilobum, } \\
\text { Staphylea bumalda, Commelina } \\
\text { communis, Solidago virga-aurea } \\
\text { var. asiatica, Cornus controversa, } \\
\text { Phryma leptostachya var. } \\
\text { asiatica, Athyrium yokoscense, } \\
\text { Viola dissecta var. } \\
\text { chaerophylloides, Youngia } \\
\text { denticulata, Syneilesis palmata, } \\
\text { Iris rossii, Asarum sieboldii, } \\
\text { Dryopteris chinensis, Sedum } \\
\text { kamtschaticum, Ainsliaea } \\
\text { acerifolia, Melampyrum roseum, } \\
\text { Carex ciliato-marginata, } \\
\text { Peucedanum terebinthaceum, } \\
\text { Smilax riparia var. ussuriensis, } \\
\text { Lysimachia clethroides, } \\
\text { Cephalanthera longibracteata, } \\
\text { Impatiens textori, Astilbe } \\
\text { chinensis var. davidii, Viola } \\
\text { rossii, Isodon japonica, } \\
\text { Asplenium incisum, Spodiopogon } \\
\text { cotulifer, Artemisia princeps, } \\
\text { Adenophora triphylla var. } \\
\text { japonica, Duchesnea chrysantha, } \\
\text { Osmunda japonica, Meehania } \\
\text { urticifolia, Hosta longipes, } \\
\text { niponicum }\end{array}$ & $\begin{array}{l}\text { Carex lanceolata, Oplismenus } \\
\text { undulatifolius, Aster scaber, } \\
\text { Spodiopogon sibiricus, } \\
\text { Artemisia keiskeana, Pyrola } \\
\text { japonica, Symplocos chinensis } \\
\text { for. pilosa, Arundinella hirta, } \\
\text { Pteridium aquilinum var. } \\
\text { latiusculum, Disporum } \\
\text { smilacinum, Carex humilis, } \\
\text { Polygonatum odoratum var. } \\
\text { pluriflorum, Isodon inflexus, } \\
\text { Smilax nipponica, Miscanthus } \\
\text { sinensis var. purpurascens, } \\
\text { Calamagrostis arundinacea, } \\
\text { Commelina communis, Carex } \\
\text { siderosticta, Chrysanthemum } \\
\text { zawadskii var. latilobum, } \\
\text { Staphylea bumalda, Solidago } \\
\text { virga-aurea var. asiatica, } \\
\text { Phryma leptostachya var. } \\
\text { asiatica, Cornus controversa, } \\
\text { Dryopteris chinensis, Viola } \\
\text { dissecta var. chaerophylloides, } \\
\text { Youngia denticulata, Athyrium } \\
\text { yokoscense, Iris rossii, Sedum } \\
\text { kamtschaticum, Carex } \\
\text { ciliato-marginata, Syneilesis } \\
\text { palmata, Smilax riparia var. } \\
\text { ussuriensis, Artemisia } \\
\text { princeps, Lysimachia } \\
\text { clethroides, Asarum sieboldii, } \\
\text { Asplenium incisum, Ainsliaea } \\
\text { acerifolia, Spodiopogon } \\
\text { cotulifer, Peucedanum } \\
\text { terebinthaceum, Melampyrum } \\
\text { roseum, Cephalanthera } \\
\text { longibracteata, Isodon } \\
\text { japonica, Osmunda japonica, } \\
\text { Impatiens textori, Duchesnea } \\
\text { chrysantha }\end{array}$ & $\begin{array}{l}\text { Oplismenus undulatifolius, } \\
\text { Carex lanceolata, Arundinella } \\
\text { hirta, Aster scaber, Pteridium } \\
\text { aquilinum var. latiusculum, } \\
\text { Spodiopogon sibiricus, Pyrola } \\
\text { japonica, Artemisia keiskeana, } \\
\text { Miscanthus sinensis var. } \\
\text { purpurascens, Symplocos } \\
\text { chinensis for. pilosa, } \\
\text { Disporum smilacinum, Carex } \\
\text { humilis, Commelina } \\
\text { communis, Polygonatum } \\
\text { odoratum var. pluriflorum, } \\
\text { Calamagrostis arundinacea, } \\
\text { Smilax nipponica, Phryma } \\
\text { leptostachya var. asiatica, } \\
\text { Staphylea bumalda, } \\
\text { Chrysanthemum zawadskii } \\
\text { var. latilobum, Solidago } \\
\text { virga-aurea var. asiatica, } \\
\text { Carex siderosticta, Carex } \\
\text { ciliato-marginata, Dryopteris } \\
\text { chinensis, Artemisia princeps } \\
\text { var. orientalis }\end{array}$ & $\begin{array}{l}\text { Rumohra aristata, Dryopteris } \\
\text { bissetiana, Dryopteris } \\
\text { erythrosora, Asplenium } \\
\text { incisum, Boehmeria } \\
\text { platanifolia, Dryopteris } \\
\text { pacifica }\end{array}$ \\
\hline Vine & $\begin{array}{l}\text { Smilax china, Cocculus trilobus, } \\
\text { Smilax sieboldii, Parthenocissus } \\
\text { tricuspidata, Pueraria } \\
\text { thunbergiana, Ampelopsis } \\
\text { brevipedunculata var. } \\
\text { heterophylla, Lonicera japonica, } \\
\text { Celastrus orbiculatus, Rubia } \\
\text { akane, Clematis apiifolia, } \\
\text { Clematis mandshurica, } \\
\text { Hydrangea serrata for. } \\
\text { acuminata, Dioscorea batatas, } \\
\text { Actinidia arguta, Vitis amurensis }\end{array}$ & $\begin{array}{l}\text { Smilax china, Cocculus } \\
\text { trilobus, Parthenocissus } \\
\text { tricuspidata, Smilax sieboldii, } \\
\text { Pueraria thunbergiana, } \\
\text { Ampelopsis brevipedunculata } \\
\text { var. heterophylla, Lonicera } \\
\text { japonica, Celastrus } \\
\text { orbiculatus, Rubia akane, } \\
\text { Clematis apiifolia, Clematis } \\
\text { mandshurica, Hydrangea } \\
\text { serrata for. acuminata, } \\
\text { Dioscorea batatas, Humulus } \\
\text { japonicus }\end{array}$ & $\begin{array}{l}\text { Smilax china, Cocculus } \\
\text { trilobus, Parthenocissus } \\
\text { tricuspidata, Pueraria } \\
\text { thunbergiana, Lonicera } \\
\text { japonica, Paederia scandens, } \\
\text { Ampelopsis brevipedunculata } \\
\text { var. heterophylla, Smilax } \\
\text { sieboldii, Celastrus } \\
\text { orbiculatus, Zelkova serrata, } \\
\text { Clematis apiifolia, Rubia } \\
\text { akane, Dioscorea batatas }\end{array}$ & $\begin{array}{l}\text { Hedera rhombea, } \\
\text { Trachelospermum asiaticum } \\
\text { var. intermedium, } \\
\text { Lemmaphyllum microphyllum, } \\
\text { Smilax china, Parthenocissus } \\
\text { tricuspidata, Lonicera } \\
\text { japonica, Akebia quinata, } \\
\text { Celastrus orbiculatus, } \\
\text { Paederia scandens, Ampelopsis } \\
\text { brevipedunculata var. } \\
\text { heterophylla, Clematis } \\
\text { apiifolia }\end{array}$ \\
\hline
\end{tabular}


이 나타났고, 초본층에 그늘사초, 큰기름새, 참 취, 맑은대쑥, 주름조개풀 등이 나타났다. 또한 덩굴식물에는 청미래덩굴, 댕댕이덩굴, 청가시 덩굴, 담쟁이덩굴, 칡 등이 나타났다.

기후변화 시나리오에 따른 2020년 천안시 온 량지수분포 따른 적응 가능한 식물종에는 교목 층에 졸참나무, 굴참나무, 소나무, 신갈나무, 상 수리나무 등이 나타났으며, 관목층에 생강나무, 개옻나무, 산초나무, 진달래, 노간주나무 등이 있었고, 초본층에 그늘사초, 주름조개풀, 참취, 큰기름새, 맑은대쑥 등이 나타났다. 덩굴성 종 에는 청미래덩굴, 댕댕이덩굴 등이 나타날 것으 로 예상된다. 2050년 온량지수에 따른 천안시 적응 가능한 식물종에는 교목층에 졸참나무, 굴 참나무, 소나무, 상수리나무, 때죽나무 등이 나 타났으며, 관목층에 개옻나무, 생강나무, 산초나 무, 진달래, 노간주나무 등이 나타났고, 초본층 에 주름조개풀, 그늘사초 등이 나타났으며, 덩 굴식물인 청미래덩굴, 댕댕이덩굴, 담쟁이덩굴 등이 나타날 것으로 예측된다. 2050년까지 공통 적으로 나타나는 식물종에는 교목층에 졸참나 무, 굴참나무, 소나무, 상수리나무 등이 있었으 며, 관목층 개옻나무, 생강나무, 산초나무, 진달 래 등이 있었고, 초본층에 주름조개풀, 그늘사 초, 새, 참취 등이 있으며. 덩굴식물인 청미래덩 굴, 댕댕이덩굴, 담쟁이덩굴 등이 공통적으로 나타나 2050년까지 적응하여 살 수 있을 것으 로 판단된다.

2099년에는 냉온대림에서 난온대림으로 변 화하여 식물종의 대부분은 상록활엽수인 난온 대림 식물종이 천안시 지역에 나타날 것으로 예 측된다. 따라서 기후변화에 따른 2099년에 적응 가능한 식물종은 교목층에는 참식나무, 후박나 무, 종가시나무, 팽나무 등이 나타났으며, 관목 층에는 까마귀쪽나무, 예덕나무, 천선과나무 등 이 나타났고, 초본층에는 가는쇠고사리, 족제비 고사리, 홍지네고사리 등이 나타났으며, 덩굴식 물은 송악, 마삭줄, 콩짜개덩굴 등이 적응하여
출현할 것으로 예측된다.

윤종학 등(2011)에 의하면 난온대 상록활엽 수의 실제 분포에서 추출한 유/무의 자료와 4 가 지 기후변수(온량지수, 최한월 최저기온, 동경 강수량, 하계강수량)를 사용하여 현재기후에서 난온대 상록활엽수의 잠재 생육지는 $28,230 \mathrm{~km}^{2}$ 로 예측하였으며, 3 종류의 기후변화 시나리오 (CCCMA-A2, CSIRO-A2, HADCM3-A2)에서는 난온대 상록활엽수의 잠재 생육지가 77,140 $89,285 \mathrm{~km}^{2}$ 변화하여 증가할 것으로 예측하였다. 박종철 등(2010)은 기후자료와 지형고도자료를 이용하여 남한의 온량지수 분포도를 작성하고 이를 통하여 지구온난화에 따른 과거 20년 (1968 1987), 최근 20년(1988 2007), 미래의 난온대 상록활엽수림대의 이동을 분석하였다. 연구 결과 과거 20 년에 비해 최근 20 년간 난온 대 상록활엽수림대의 면적이 약 2.7 배 증가하였 으며 미래에는 서해안을 따라 충남 내륙방면으 로 넓게 퍼져 북상하고, 동해 해안선을 따라 좁 고 길게 북상할 것으로 예측하였다. 그러나 본 연구는 난온대 상록활엽수의 수종을 연구한 것 이 아니라 기후변화에 따른 제한된 지역에서 나 타날 수 있는 적응 가능한 식물종에 대한 연구 이므로 연구대상에 대한 차이가 나타난다. 그렇 지만 기후변화에 따라 한반도는 난온대의 상록 활엽수림으로 변화하는 것에 대해서 큰 이견이 없을 것으로 판단된다.

\section{IV. 결 론}

IPCC 4차보고서의 기후변화 시나리오 중 온 실가스 저감노력 없이 지금과 같은 경제발전을 하였을 때의 시나리오인 RCP 8.5 를 이용하여 기후변화에 따른 천안시의 온량지수 변화 및 산 림기후대의 변화를 예측하였다. 또한 우리나라 에 분포하고 있는 자생 식물 4,961 종 중 위치정 보를 가지고 있는 1,522종에 대하여 2010년 현 재 온량지수에 따른 식물종의 온량지수 분포범 
위를 이용하여 천안시의 2010년, 2020년, 2050 년, 2099년에 온량지수 분포범위를 중첩하여 적 응 가능한 식물종을 선정하였다.

1. 기후변화 시나리오에 따른 천안시 산림기 후대의 변화는 냉온대 중부림에서 2099년에 난 온대림으로 변화할 것으로 예상된다.

2. 천안시 적응 가능한 식물종 중 2010년부터 2050년까지 공통적으로 적응 가능한 식물종은 교목층에 졸참나무, 굴참나무, 소나무, 신갈나 무, 상수리나무를 포함하여 18 종이 나타났으며, 관목층에 개옻나무, 생강나무, 산초나무, 진달래 를 포함하여 28종이 나타났고, 초본층에 주름조 개풀, 그늘사초, 새, 참취를 포함한 24종이 있으 며, 덩굴성식물인 청미래덩굴, 댕댕이덩굴을 포 함한 12종들이 2050년까지 적응하여 살 수 있을 것으로 판단된다. 2099년에는 냉온대림에서 난 온대림으로 변화하여 냉온대 식물종에서 난온 대 식물종인 상록활엽수림이 나타날 것으로 예 측된다. 따라서 2099년에 적응 가능한 식물종은 교목층에 참식나무, 후박나무, 종가시나무, 팽나 무 등이 나타났으며, 관목층에 까마귀쪽나무, 예 덕나무, 천선과나무 등이 나타났고, 초본층에 가 는쇠고사리, 족제비고사리, 홍지네고사리 등이 나타났으며, 덩굴성 식물은 송악, 마삭줄, 콩짜 개덩굴 등이 나타날 것으로 판단된다.

기후변화 시나리오를 이용하여 대상 지역인 천안시의 온량지수 변화 따른 적응 가능한 식물 종을 분석하였다. 이는 향후 기후변화 시나리오 를 이용하여 각 지역에 적합한 식재 식물종 및 적응 가능한 식물종을 선정하는데 기초 자료로 활용될 수 있을 것으로 기대된다.

\section{인 용 문 헌}

Kang, Hyun-Kyoung and Bang, Kwang-Ja. 2001.

Restoration Model of Quercus mongolica Community in the Case of Korean National Capital Region. Journal of Korean institute of landscape architecture 28(6):1-15.

Kim, Kwi-Gon $\cdot$ Cho, Dong-Gil $\cdot$ Kim, Nam-Choon and Min, Byung-Mee. 2000. A Study on the Development of Techniques for Urban Forest Restoration and Management. J. Korean Env. Res. \& Reveg. Tech. 3(1) : 27-37

Park, Jong-Chul - Yang, Keum-Chul and Jang, Dong-Ho. 2010. The Movement of Evergreen Broad-Leaved Forest Zone in the Warm Temperate Region Due to Climate Change in South Korea. Journal of Climate Research 5(1) : 29-41.

Sim, Woo Kyung. 1988. Studies on Landscape Planting Design( I ) -With SpeciAl refErence to the Selection of til:es in the Landscape -. Journal of Korean institute of landscape architecture 15(3) : 1-10.

Byun, Jung-Yeon $\cdot$ Lee, Woo-Kyun $\cdot$ Choi, SungHo - Oh, Su-Hyun - Yoo, Seong-Jin - Kwon, Tae-Sung $\cdot$ Sung, Joo-Han and Woo, Jae-Wook. 2012. Vulnerability Assessment for Forest Ecosystem to Climate Change Based on Spatiotemporal Information. Korean Journal of Remote Sensing 28(1) : 159-169.

Yang, Keum-Chul. 2001. Classification of Major Habitats Based on the Climatic Conditions and Topographic Feeatures in Korea. Thesis for the Degree of Ph.D. Department of Biology Graduate School Chung-Ang University.

Yun, Jong-Hak • Katsuhiro Nakao • Park, Chan-Ho • Lee, Byoung-Yoon and Oh, Kyoung-Hee. 2011. Change Prediction for Potential Habitats of Warm-temperate Evergreen Broad-leaved Trees in Korea by Climate Change. Kor. J. Env. Eco. 25(4) : 590-600.

Lee, Kyong-Jae $\cdot$ Cho, Woo and Han, Bong-Ho. 1996. Restoration and Status of Urban Ecosystem in Seoul(1)-Plant Community Structure in 
Forest Area-. Kor. J. Env. Eco. 10(1) : 137-127.

Hough, M. 1983. City from and natural process. Croom Helm, London, 281p.

IPCC. 2007. Climate change 2007 : Synthesis Report. IPCC Fourth Assessment Report. Geneva, Switzerland, 104p.

Kira, T. 1945. A new Classification of Climate in Eastern Asia as the basis for Agricultural Geography. Horticultural Institute. Kyoto Univ, Kyoto.

Lee, W. T. and Yim, Y. J. 1978. Studies on the distribution of vascular plants in the Korean Peninsula. Korean J. Pl. Taxon. 8, Supplement : $1-33$.
Suh, M. S. • Lee, J. R. • Kang, J. H. • Lee, D. K. and Ahn, M. H. 2005. On the relationship between seasonal change of vegetation and climate elements in East Asia, Asia-Pacific Journal of Atmospheric Sciences 41(4): 557-570.

Yim, Y. J. 1977. Distribution of Forest Vegetation and Climate in the Korean Peninsula III. Distribution of Tree Species Along the Thermal Gradient. Japanses Journal of Ecology $27: 177-189$.

Yim, Y. J. and T. Kira. 1975. Distribution of forest vegetation and climate in the Korean peninsula. I. Distribution of some indices of thermal climate. Japanese J. Ecol. 25 : 77-88. 